\title{
KRAS and BRAF Mutations as survival prognostic factors for Metastatic Colorectal Cancer patients after Lung metastasectomy: A Systematic Review and Meta-Analysis
}

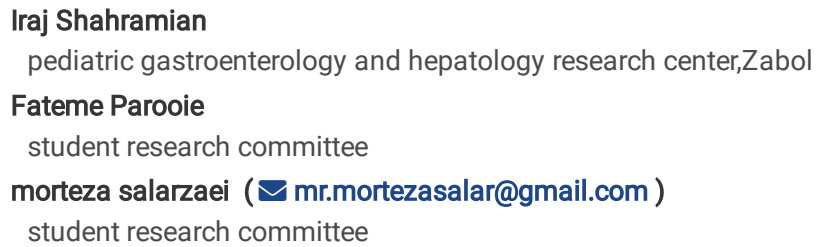

Research article

Keywords: Colorectal cancer biomarkers, Colorectal cancer prognosis, KRAS, BRAF, Lung metastases

Posted Date: January 9th, 2020

DOI: https://doi.org/10.21203/rs.2.20466/v1

License: (c) (i) This work is licensed under a Creative Commons Attribution 4.0 International License. Read Full License 


\section{Abstract}

Introduction

While knowledge has grown extensively regarding the impact of mutations on colorectal cancer prognosis, their role in outcomes after pulmonary metastasectomy (PM) remains minimally understood. Therefore, in this paper, we conduct a systematic review and meta-analysis of retrospective and prospective studies to evaluate whether KRAS or BRAF mutation status can be independent predictors in colorectal cancer patients undergoing complete lung metastasis surgery.

Methods

A systematic literature review was performed to identify articles reporting overall survival (OS) of patients who underwent lung metastasectomy for colorectal cancer lung metastases (CRLM), stratified according to KRAS and BRAF mutational status. Hazard ratios (HRs) from multivariate analyses were pooled in the meta-analysis.

Results

9 studies, including 1833 patients, were eligible for the meta-analysis. Based on the random effect model, the total frequency of KRAS mutations in 1305 patients who had undergone the lung metastasectomy was $45 \%$ and the total 5 -year OS in these patients was $55.7 \%$. five of them reported OS stratified according to KRAS mutation. The pooled analysis revealed that KRAS mutation was negatively associated with 0 ( 1.341-2.089; $\mathrm{P}<.001)$. the rate of KRAS mutations were lower in the studies with higher male to female ratio. There was statistically significant linear trend in univariate meta-regression to explain effect size variation by male to female ratio of study with coefficient $=0.47(95 \% \mathrm{Cl} 0.03,0.91)$, $\mathrm{P}=0.03$. disease free survival (DFS), thoracic metastases and origin of primary tumor were significantly influenced by KRAS mutation status.

Conclusions

Our meta-analysis confirms the KRAS mutation as a strong and predictive biomarker which makes overall survival lower in patients with colorectal cancer undergoing pulmonary metastasis surgery. Certainly, this interesting evidence represents the first step towards a deeper understanding of the molecular mechanisms underlying tumor behavior and patient outcomes in a subgroup of clinically selected colorectal cancer patients. By considering tumor molecular characteristics and other clinical-pathological factors, our results confirm the use of new therapeutic models to predict outcomes of patients undergoing colorectal lung metastasis surgery and to isolate both systemic and loco-regional treatment strategies.

\section{Introduction}

Colorectal cancer is the third most common cancer and the second leading cause of cancer deaths in the world. Despite advances in its treatment, colorectal cancer is still one of the leading causes of cancer deaths (1). Reports show that in $25 \%-30 \%$ of patients with metastatic disease, the lung is the most common extra-abdominal metastatic site (2). Approximately $10 \%-20 \%$ of all patients with colorectal cancer develop pulmonary metastasis during the course of their disease $(3,4)$. Therefore, identifying high-risk patients with pulmonary metastasis is one of the current research areas $(5-7)$. Pulmonary metastasectomy is an integral part of the interdisciplinary treatment of these patients. Although randomized, controlled trials on pulmonary metastasectomy have not been performed, resection of metastases via a multidisciplinary treatment program is crucial for selective patients $(8,9)$. Besides, the concept of repeated metastasectomy for recurrent disease leads to long-term treatment in metastatic colorectal cancer $(10,11)$. Predicting the outcome of treatment for patients with recurrent pulmonary metastasis is an obstacle in oncology surgery (12). Prior identification of patients at high risk of pulmonary recurrence may influence the treatment strategy. Therefore, the search for precise biomarkers in pulmonary metastasectomy is increasing (13). Numerous studies have used genetic, familial, and sporadic mutations in the pathogenesis of colorectal cancer. Besides, the association of these mutations with poorer prognosis has also been demonstrated. One study has found that mutations in RAS genes are independent predictors of overall survival and DFS in patients with colorectal cancer (14). Also, a comprehensive population-based study showed that mutations can increase the risk of mortality (15). Mutations in APC and TP53 tumors may be hereditary especially familial adenomatous polyposis and Li-Fraumeni syndrome but may represent a sporadic process in the development of colorectal cancer $(16,17)$. Like RAS, these two mutated genes are also used in the pathogenesis of colorectal cancer (18-20). Colorectal cancer patients with liver metastases who have a mutated KRAS gene have been shown to have lower overall survival (OS) and DFS(disease free survival) after liver metastasectomy (21). However, despite all available data from the assessment of the effect of genetic mutations on this disease, the role of these mutations after pulmonary metastasectomy for pulmonary metastases in colorectal cancer is not well understood. Little data are available about the role of KRAS mutations in predicting death after pulmonary metastases, but RAS family mutations have not been fully evaluated $(22,23)$. Therefore, in this paper, we conduct a systematic review and meta-analysis of retrospective and prospective studies to evaluate whether KRAS or BRAF mutation status can be independent predictors in colorectal cancer patients undergoing complete lung metastasis surgery.

\section{Materials And Methods Objectives}

The purpose of this analysis was to evaluate the status of the KRAS and BRAF mutations in retrospective and prospective studies on patients undergoing radical surgery for colorectal cancer lung metastases. The primary objective was to evaluate overall survival and the secondary objective was to determine the disease-free survival (DFS)

\section{Data sources and search strategies}


A systematic review of the literature was conducted in November 2019, and we reviewed MEDLINE/PubMed, the Cochrane Library, and ClinicalTrials.gov for further citations or experiments from January 2000 to November 2019. The search criteria were limited to human studies published in English. The medical terms for PubMed searches were 'BRAF' or 'KRAS'; 'colon cancer' or 'colorectal cancer' or 'rectal' or 'rectum'; 'metastasis' or 'metastatic' or 'metastases' or 'metastasectomy'; and 'lung' or 'pulmonary'.

\section{Selection criteria}

Selected articles had to meet the following selection criteria: (1) To address metastatic colorectal cancer patients undergoing complete lung metastatic resection surgery; (2) To report the results of genetic tests for KRAS or BRAF mutation status from CRLM(colorectal lung metastasectomy) specimens isolated from metastatic colorectal cancer; and (3) To report disease-free survival (DFS) and/or overall survival (OS)results according to the mutation status. This meta-analysis included studies published since 2000 to illustrate the results of recent surgical techniques. Duplicate articles or repeated articles that were selected based on the same patient group were not included in this meta-analysis: If another cohort article was identified, we would select one with the largest number of patients and if not specified, we would have chosen the older article. The exclusion criteria were: The article was not published in English; the initial cause was not colorectal cancer; and the initial site of metastasis was not lung (R2 resection).

\section{Data extraction}

The data were extracted independently and based on preferred reporting of cases for systematic reviews and meta-analyses. Two authors [FP] and [MS] selected studies according to the previously described selection criteria. After the first selection, another author [ISH] was consulted if necessary. A predefined protocol was used to extract the data from each study including the first author's name, year of publication, the name of journal, study period, sample size, research design, demographic characteristics, and BRAF and KRAS mutation status, overall and free-disease survival, and variables affecting the univariate and multivariate analysis. The overall survival and disease-free survival were categorized based on the mutation status in each cohort study. Besides, the relative hazard ratio (HR) was measured at a 95\% confidence interval, and the Kaplan-Meier survival analysis was used in all articles.

\section{Statistical analysis}

This meta-analysis was performed using the inverse-variance method, in which the specific weight of each study was calculated as the standard error square among the studies reviewed. Heterogeneity among studies was assessed using Cochran $\mathrm{Q}$ and $\mathrm{I}^{2}$ statistics. The fixed and random effects were reported.

\section{Results}

\section{Literature Search Result}

The electronic search provided a total of 1198 results. After screening, 257 were eliminated because they were not in English language and/or duplicates; 684 were excluded because they were reviews, editorial letters, case reports, no full text available or no quality. Further, we excluded 249 articles because they included liver metastases, more than 1 (lung) metastatic site, pathways other than KRAS and BRAF, or were not focused on the effect of KRAS and BRAF mutations after lung metastasectomy as the main topic. At the end of the review process, 9 studies were identified as meeting the inclusion criteria of this review. These articles constitute the study population (Fig. 1). Study characteristics are shown in Table 1. The Cochrane database of systematic review was then cross-checked to ensure that no similar systematic reviews had been undertaken. 
characteristics for the included studies

\begin{tabular}{|c|c|c|c|c|c|c|c|c|c|c|c|c|}
\hline \multirow[t]{3}{*}{ Author } & \multirow[t]{3}{*}{ year } & \multirow[t]{3}{*}{ Country } & \multirow[t]{3}{*}{ Duration } & \multirow{3}{*}{$\begin{array}{l}\text { Mean } \\
\text { age }\end{array}$} & \multirow{3}{*}{$\begin{array}{l}\text { Male to } \\
\text { female }\end{array}$} & \multirow{3}{*}{$\begin{array}{l}\text { mean } \\
\text { follow } \\
\text { up } \\
\text { (Months) }\end{array}$} & \multirow[t]{3}{*}{ Participant } & \multirow{3}{*}{$\begin{array}{l}\text { Type of } \\
\text { study }\end{array}$} & \multicolumn{4}{|c|}{ Molecular Analysis } \\
\hline & & & & & & & & & KRAS & & & BF \\
\hline & & & & & & & & & Mutation & WT & $\begin{array}{l}\text { OS } \\
\text { (months) }\end{array}$ & $\mathbf{M}$ \\
\hline $\begin{array}{l}\text { Zabaleta } \\
24\end{array}$ & 2014 & Spain & $\begin{array}{l}1998- \\
2010\end{array}$ & $\begin{array}{l}65.7 \\
(40- \\
82)\end{array}$ & $64 / 26$ & 58.6 & 90 & Retrospective & $30(0.33)$ & & $\begin{array}{l}84(70.4- \\
97.6)\end{array}$ & - \\
\hline Renaud $^{25}$ & 2019 & Italy & $\begin{array}{l}2004- \\
2014\end{array}$ & 65 & $106 / 62$ & 62 & 168 & Retrospective & $95(0.56)$ & $73(0.44)$ & $\begin{array}{l}101(75.01- \\
126.89)\end{array}$ & - \\
\hline Renaud 26 & 2015 & France & $\begin{array}{l}1998- \\
2011\end{array}$ & - & $112 / 68$ & - & 180 & Retrospective & $93(0.52)$ & - & $\begin{array}{l}98(83.33- \\
112.66)\end{array}$ & 19 \\
\hline Pereira 27 & 2015 & USA & $\begin{array}{l}2008- \\
2010\end{array}$ & $\begin{array}{l}55(25- \\
85)\end{array}$ & $291 / 203$ & 26 & 494 & Retrospective & $202(0.41)$ & $292(0.52)$ & - & - \\
\hline Corsini 28 & 2019 & USA & $\begin{array}{l}2011- \\
2017\end{array}$ & $\begin{array}{l}57(41- \\
73)\end{array}$ & $70 / 60$ & 36.2 & 130 & Prospective & $82(0.63)$ & - & - & - \\
\hline Ghidini 29 & 2019 & Italy & $\begin{array}{l}1997- \\
2009\end{array}$ & $\begin{array}{l}65.4 \\
(33.4- \\
80.1)\end{array}$ & $27 / 48$ & 82.9 & 75 & Retrospective & $27(0.36)$ & $48(0.64)$ & 36.6 & - \\
\hline $\begin{array}{l}\text { Schweiger } \\
30\end{array}$ & 2014 & Austria & $\begin{array}{l}2009- \\
2012\end{array}$ & $\begin{array}{l}\text { 64(37- } \\
79)\end{array}$ & $20 / 19$ & 27 & 39 & Prospective & $18(0.46)$ & $21(0.54)$ & - & 0 \\
\hline $\mathrm{Kim}^{31}$ & 2017 & Korea & $\begin{array}{l}2005- \\
2015\end{array}$ & $\begin{array}{l}56(33- \\
76)\end{array}$ & $77 / 52$ & 46.4 & 129 & Retrospective & $19(0.15)$ & $31(0.24)$ & - & $1(1$ \\
\hline Liang 32 & 2018 & China & $\begin{array}{l}2011- \\
2014\end{array}$ & $\begin{array}{l}57.2 \pm \\
11.2\end{array}$ & $145 / 143$ & 46.5 & 421 & Retrospective & $221(0.54)$ & - & - & - \\
\hline
\end{tabular}

\section{Case Volume, Mutational Status, and Clinical Characteristics}

The total number of patients included in these studies was 1726, of whom $41 \%$ (787 patients) were KRAS-mutated. The mutation rate of KRAS ranges from $15 \%$ to $63 \%$. BRAF mutation was analyzed only in 3 of 9 studies and it occurred in 20 patients (5.7\%; Table 1). All patients included underwent macroscopic complete lung metastases resection.

\section{Kirsten Rat Sarcoma Viral Oncogene Homolog (KRAS) Mutational Status and OS}

four of 9 studies reported OS after resection of CRC lung metastases, stratified according to KRAS mutation. One study did not perform the multivariate analysis because KRAS status was not significant in the univariate analysis. One study did not provide the OS stratified according to KRAS status, but the multivariate HR of OS according to KRAS status was available. The Three studies for which HRs were available were then pooled in the meta-analysis, which at the end with these constraints included 699 patients. The KRAS mutation rate was $41 \%$ (Figure 3 ). The pooled analysis, using a fixed effect model, revealed that KRAS mutation was negatively associated with OS (HR, 1.64; 95\% Cl, 1.12-2.16; P . .001)(Figure 2a). Similarly, using a random effect model, KRAS mutation was negatively associated with OS (HR, 1.64; 95\% Cl, 1.12-2.16; $\mathrm{P}<0.24)$ (Figure 2a).

\section{B-Viral Oncogene Homolog B1 (BRAF) Mutational Status and OS:}

Only 3 of 9 studies analyzed OS stratified according to BRAF mutation. These studies have no provided the HR data of the multivariate analysis regarding OS according to BRAF mutational status. These 3 studies were pooled in a separate meta-analysis.

\section{META-ANALYSIS OF frequency of KRAS and BRAF mutations :}

Based on the random effect model, the total frequency of KRAS mutations in 1726 patients who had undergone the lung metastasectomy was $41 \%$ ( $95 \%$ confidence interval [Cl]:39\%-44\%, I2 =94.3\%) (Table 1, Figure 3). BRAF mutation was analyzed only in 3 of 8 studies and it occurred in 20 patients $(5.7 \%)$ (Table 1).

\section{META-ANALYSIS OF frequency of 5-year OS :}

Based on the random effect model, the total 5 -year OS in patients who had undergone the lung metastasectomy was $55.7 \%$ (95\% confidence interval [Cl]:51.8\%-59.5\%, I2 = 89.9\%).(Table 1) 
Meta-regression finding based on the mean of age and frequency of KRAS mutations:

The studies' meta-regression was according to the association between frequency of KRAS mutations and the mean age of study and the overall rate of KRAS mutations. There was no statistically significant linear trend in univariate meta-regression to explain effect size variation by mean of age of study with coefficient $=0.14(95 \% \mathrm{Cl}-2.17,2.46), \mathrm{P}=0.88$ (Figure $4 \mathrm{a})$.

\section{Meta-regression finding based on the publication year and frequency of KRAS mutations:}

The studies' meta-regression was according to the association between the publication year of study and the overall rate of KRAS mutations. It showed the overall rate of KRAS mutations was upper in newer studies than the older ones (Figure 4b). But there was no statistically significant linear trend in univariate meta-regression to explain effect size variation by publication year of study with coefficient $=-35.63(95 \% \mathrm{Cl}-171.21,99.94)$, $\mathrm{P}=0.71$ (Figure $4 \mathrm{~b})$.

\section{Meta-regression finding based on the male to female ratio of study and frequency of KRAS mutations:}

The overall rate of KRAS mutations based on the female to male ratio of the studies is showed in (Figure 4-c), the rate of KRAS mutations was lower in studies with higher male to female ratio. There was statistically significant linear trend in univariate meta-regression to explain effect size variation by male to female ratio of study with coefficient $=0.47(95 \% \mathrm{Cl} 0.03,0.91), \mathrm{P}=0.03$.

\section{Sub-group analysis}

\section{Comparison of the prevalence of other prognostic factors in WT and mKRAS patients :}

The overall prevalence of CEA $\geq 5$ based on four articles was $53 \%\left(95 \% \mathrm{Cl}: 47 \%-58 \%, \mathrm{I}^{2}: 92.2\right), 52 \%\left(95 \% \mathrm{Cl}: 47 \%-58 \%, \mathrm{I}^{2}: 92.2\right)$ for WT and mKRAS groups respectively(24-26,32), The overall prevalence of DFS $<12$ months based on four articles(24-26,32) was 18.5\%(95\%Cl:12\%-24\% , I2:91) , 36\%(95\%Cl:29\%-43\% , $\left.\mathrm{I}^{2}: 93\right)$ for WT and mKRAS groups respectively. The overall prevalence of liver metastases based on 7 articles(24-28,30,32) was $56 \%\left(95 \% \mathrm{Cl}: 53 \%-59 \%, \mathrm{I}^{2}: 98.7\right)$ and $54 \%\left(95 \% \mathrm{Cl}: 55 \%-58 \%, \mathrm{I}^{2}: 97.6\right)$ for WT and mKRAS groups respectively. The overall prevalence of thoracic metastases based on four articles (24,25,27,28) was $20 \%\left(95 \% \mathrm{Cl}: 16 \%-24 \%, \mathrm{I}^{2}: 80.7\right)$ and $22 \%\left(95 \% \mathrm{Cl}: 18 \%-27 \%, \mathrm{I}^{2}: 90\right)$ for WT and mKRAS groups respectively. The overall prevalence of rectum as the first origin of cancer based on 5 articles $(24,26,28-30)$ was $32 \%\left(95 \% \mathrm{Cl}: 28 \%-36 \%, \mathrm{I}^{2}: 95\right), 29 \%\left(95 \% \mathrm{Cl}: 24 \%-33 \%, \mathrm{I}^{2}: 92\right)$ for WT and mKRAS group respectively.

\section{Comparison of OS and DRS between WT and mKRAS patients}

The mean overall survival time based on 7 articles $(24-29,32)$ were 66 months in WT and 54 months in mKRAS colorectal cancer patients undergoing lung metastasectomy. The mean overall disease free survival time based on 3 articles $(24,29,32)$ were 12 months in WT and 10.5 months in mKRAS colorectal cancer patients undergoing lung metastasectomy.

\section{publication bias:}

Funnel plot in (Figure 4d) shows no indication of publication bias. It is shows in funnel plot symmetrically. Circles' size shows the weight of studies (bigger circles shows more sample and smaller circles shows fewer sample).

\section{Discussion}

Pulmonary metastasectomy for colorectal cancer is well accepted in the field of thoracic surgery, although due to the lack of comparative data between simple follow-up and surgery, it is still a subject of discussion. Because lung parenchymal resection can cause complications and alter respiratory function, surgery should be avoided at high risk. To help evaluate patients for metastasectomy, several studies have attempted to identify prognostic factors such as high preoperative CEA level, short-term disease-free survival (DFS), presence of liver and thoracic metastases, incomplete resection, or LNI (33-36) However, in spite of these predictive biomarkers, in some patients thoracic surgery is useless, leading to the search for other predictive markers. Over the past few years, the identification of molecular changes in tumors has led to better patient management and the identification of subgroups of patients with different responses to different drugs or predictors, such as EGFR-activating mutations in non-small cell lung cancer (37). In patients with colorectal cancer, two biomarkers have been considered: the KRAS 12/13 codon mutation and the V600E mutation from BRAF gene. The role of molecular biomarkers, such as KRAS and BRAF, in advanced and non-surgical disease is well established. However, its potential use in patients with colorectal cancer with pulmonary metastasis undergone surgery has not yet been known. Most published papers have reported a prevalence of KRAS mutation in local and metastatic colorectal cancer ranging from 35 to $55 \%$. In this meta-analysis, the prevalence of KRAS mutation was $41 \%$ and the prevalence of BRAF mutation in patients with colorectal cancer after lung metastasectomy was $5.7 \%$. We considered the results of 9 studies on the relationship between KRAS and BRAF mutation status and overall survival or disease-free survival (DFS) in patients with colorectal cancer undergoing pulmonary metastatic surgery. These studies evaluated overall survival and disease-free survival for patients undergoing colorectal cancer metastasectomy classified by BRAF and KRAS mutation status and showed that overall KRAS mutation is lower compared to the wild type (WT) population. There is lots of evidence that RAS mutation has a negative predictive role in patients with metastatic colorectal cancer $(39,40)$. In fact, the KRAS mutation has weaker biology and faster onset, and aggressive metastasis, especially in the lungs and bones that challenges clinical decision making (41-46). In this meta-analysis, we found that in patients whose tumors had a KRAS mutation, overall survival and disease-free survival were lower, with an average KRAS mutation of $41 \%$. Besides, the estimated overall survival was 54 months for the mKRAS (KRAS mutation) patients compared to 66 months for the non-mutated variant. Also, in line with other studies, the HR was 1.64 ) $95 \%$ confidence interval) and equal to $1.12-2.16$ for mKRAS $(p<0.24)$ which is considered as a negative predictor. However, Zabaleta et al. concluded that the presence of a K-RAS mutation in lung metastases did not affect overall survival, but was associated with a higher rate of pulmonary recurrence (34). Our 
findings are consistent with two recent meta-analyses. In their meta-analysis, Tosi et al stated that KRAS mutation had a negative relationship with overall survival and disease-free survival in patients undergoing complete liver surgery for colorectal cancer metastases. Passiglia et al. showed that KRAS mutation decreases the overall survival ( $H R=1.65$ and $1.23-2.21$ at $95 \%$ confidence interval) and disease-free survival $(H R=1.86 \%$ and $1.51-2.30$ at a $95 \%$ confidence interval) in patients undergoing liver metastasis resection for colorectal cancer (48) Some studies have shown a higher prevalence of pulmonary metastasis/recurrence in patients with KRAS mutation $(17,18)$. In this meta-analysis, the incidence of KRAS mutation in patients undergoing lung metastasectomy was $41 \%$. Our results are consistent with two previous studies that reported a higher rate of mKRAS in lung metastases than in liver metastases in patients with primary colorectal cancer. In fact, Tie et al. (49) reported $62 \%$ mKRAS in lung metastases versus $32.3 \%$ in liver metastases. Besides, Cejas et al. reported 57\% mKRAS in lung metastases versus 35\% in liver metastases. The prevalence of BRAF mutation in patients with colorectal cancer after lung metastasectomy was only $5.7 \%$ and there was not sufficient data to evaluate the overall survival of mBRAF patients, so we cannot consider mBRAF as a negative predictor. Nevertheless, this low percentage may be related to the low number of studies (as the BRAF mutation was evaluated in only 3 of the 8 selected studies). However, both studies mentioned above reported the BRAF mutation as a negative predictor. Concerning BRAF mutation, even in a small subset of patients, most of the published studies have identified BRAF mutations from early tumor specimens as a strong negative predictive marker in metastatic colorectal cancer (51) which has proven to be more aggressive and chemically refractory than malignant tumors (52). The prevalence of BRAF mutation in patients with colorectal cancer after pulmonary metastasectomy was $5.7 \%$ in our study, which is consistent with previous studies [5-10\%] (53). The low percentage of BRAF mutations in this group of colorectal cancer patients may limit its clinical use as a predictive biomarker for routine use but does not affect its scientific significance as well as its potential consequences for patients. We also performed a subgroup meta-analysis to evaluate the prevalence of other predictive factors such as high preoperative CEA level (CEA $\geq 5$ ), low disease-free survival (less than 12 months), presence of hepatic metastases, number of thoracic metastases $(>1)$, and the origin of the primary tumor in MKRAS and WT metastatic pulmonary patients to assess significant differences. We found that disease-free survival, thoracic metastases, and primary tumor origin were affected by KRAS mutation status, with disease-free survival being significantly lower and the number of thoracic metastases significantly greater in mKRAS patients. The origin of most mKRAS tumors was colon ) $71 \%$ ) and the rectum in $32 \%$ of WT was the primary tumor origin.

\section{Limitations}

This meta-analysis was conducted with several limitations. First, although the reviewed studies were limited to those conducted on patients with pulmonary metastasis who had undergone pulmonary metastasectomy and included studies from 2000 to recent studies, 9 selected studies differed in sample size and other criteria for patient selection, which was reflected as heterogeneity in Cochran Q and $\mathrm{I}^{2}$ statistics. Also, this meta-analysis did not consider possible differences between different variants of KRAS mutations because KRAS mutations were not distinguished in the existing studies and therefore no information was extracted for analysis.

\section{Conclusion}

Our meta-analysis confirms the KRAS mutation as a strong and predictive biomarker which makes overall survival lower in patients with colorectal cancer undergoing pulmonary metastasis surgery. Certainly, this interesting evidence represents the first step towards a deeper understanding of the molecular mechanisms underlying tumor behavior and patient outcomes in a subgroup of clinically selected colorectal cancer patients. By considering tumor molecular characteristics and other clinical-pathological factors, our results confirm the use of new therapeutic models to predict outcomes of patients undergoing colorectal lung metastasis surgery and to isolate both systemic and loco-regional treatment strategies.

\section{Abbreviations}

Overall survival (OS), Colorectal cancer (CRC) , Kirsten rat sarcoma viral oncogene homolog (KRAS), v-raf murine sarcoma b-viral oncogene homolog B1 (BRAF) ,WT : wild-type, OS indicates overall survival. HR: hazard ratio; Cl: confidence intervals; N.A: not available

\section{Declarations}

Ethics Approval and Consent to Participate: not applicable.

Consent for publication: not applicable

Availability of data and supporting materials section: Please contact author for data requests

Competing Interests: Neither of the authors has any conflict of interest to disclose

Funding: not applicable

\section{Author contribution:}

ISH participated in Conception and design of the study, library searches and assembling relevant literature, critical review of the paper, supervising writing of the paper, Database management.MS and FP participated in Data collection, library searches and assembling relevant literature, writing the paper, and critical review of the paper. ISH participated in Data collection, library searches and assembling relevant literature, writing the paper, analysis of the data and critical review of the paper. All authors read and approved the final manuscript.

We confirm that we have read the Journal's position on issues involved in ethical publication and affirm that this report is consistent with those guidelines. 


\section{References}

1. Siegel R, Naishadham D, Jemal A. Cancer statistics, 2013. CA Cancer J Clin. 2013;63(1):11-30.

2. Labianca R, Beretta GD, Kildani B, et al. Colon cancer. Crit Rev Oncol Hematol. 2010;74:106-133.

3. August DA, Ottow RT, Sugarbaker PH. Clinical perspective of human colorectal cancer metastasis. Cancer Metastasis Rev. 1984;3:303-324.

4. McCormack PM, Burt ME, Bains MS, Martini N, Rusch VW, Ginsberg RJ. Lung resection for colorectal metastases. 10-Year results. Arch Surg. 1992;127:1403-1406.

5. Siegel R, Naishadham D, Jemal A. Cancer statistics, 2013. CA Cancer J Clin. 2013;63(1):11-30.

6. Van Schil P. Lung metastases and isolated lung perfusion. New York: Nova Science Publishers; 2007.

7. Mitry E, Guiu B, Cosconea S, Jooste V, Faivre J, Bouvier AM. Epidemiology, management and prognosis of colorectal cancer with lung metastases: a 30year population-based study. Gut. 2010;59(10):1383-8.

8. Pfannschmidt J, Hoffmann H, Dienemann H. Reported outcome factors for pulmonary resection in metastatic colorectal cancer. J Thorac Oncol. 2010;5(6 Suppl 2):S172-8.

9. Treasure T, Fallowfield L, Farewell V, et al. Pulmonary metas- tasectomy in colorectal cancer: time for a trial. Eur J SurgOncol. 2009;35(7):686-9.

10. Kandioler D, Kromer E, Tuchler H, et al. Long-term results after repeated surgical removal of pulmonary metastases. Ann Thorac Surg. 1998;65(4):909-12.

11. Salah S, Watanabe K, Park JS, et al. Repeated resection of colorectal cancer pulmonary oligometastases: pooled analysisand prognostic assessment. Ann Surg Oncol. 2013;20(6):1955-61.

12. Gonzalez M, Poncet A, Combescure C, Robert J, Ris HB, Gervaz P. Risk factors for survival after lung metastasectomy incolo- rectal cancer patients: a systematic review and meta-analysis. Ann Surg Oncol. 2013;20(2):572-9.

13. Schweiger T, Lang G, Klepetko W, Hoetzenecker K. Prognostic factors in pulmonary metastasectomy: spotlight on molecular and radiological markers. Eur J Cardiothorac Surg. 2013. doi:10. 1093/ejcts/ezt288.

14. Liu J, Zeng W, Huang C, Wang J, Yang D, Ma D. Predictive and prognostic implications of mutation profiling and microsatellite instability status in patients with metastatic colorectal carcinoma. Gastroenterol Res Pract. 2018;2018:4585802.

15. Charlton ME, Kahl AR, Greenbaum AA, et al. KRAS testing, tumor location, and survival in patients with stage IV colorectal cancer: SEER 2010-2013. J Natl Compr Canc Netw. 2017;15:1484-1493

16. Raskov H, Pommergaard HC, Burcharth J, Rosenberg J. Colorectal carcinogenesis--update and perspectives. World J Gastroenterol. 2014;20:1815118164.

17. Kratz CP, Achatz MI, Brugieres L, et al. Cancer screening recom- mendations for individuals with Li-Fraumeni Syndrome. Clin Cancer Res. 2017;23:e38-e45.

18. Malhotra P, Anwar M, Nanda N, et al. Alterations in K-ras, APC and p53-multiple genetic pathway in colorectal cancer among Indians. Tumour Biol. 2013;34:1901-1911.

19. Drost J, van Jaarsveld RH, Ponsioen B, et al. Sequential cancer mutations in cultured human intestinal stem cells. Nature. 2015;521:43-47.

20. Palacio-Rua KA, Isaza-Jimenez LF, Ahumada-Rodriguez E, Muneton- Pena CM. Genetic analysis in APC, KRAS, and TP53 in patients with stomach and colon cancer. Rev Gastroenterol Mex. 2014;79:79-89.

21. Passiglia F, Bronte G, Bazan V, Galvano A, Vincenzi B, Russo A. Can KRAS and BRAF mutations limit the benefit of liver resection in metastatic colorectal cancer patients? A systematic review and meta- analysis. Crit Rev Oncol Hematol. 2016;99:150-157

22. Renaud S, Romain B, Falcoz PE, et al. KRAS and BRAF mutations are prognostic biomarkers in patients undergoing lung metastasectomy of colorectal cancer. Br J Cancer. 2015;112:720-728.

23. Moorcraft SY, Jones T, Walker BA, et al. Molecular profiling of colorectal pulmonary metastases and primary tumours: implications for targeted treatment. Oncotarget. 2017;8:64999-65008

24. Zabaleta J, Aguinagalde B, Izquierdo JM, Bazterargui N, Laguna SM, Martin-Arruti M, Lobo C, Emparanza JI. The presence of mutations in the K-RAS gene does not affect survival after resection of pulmonary metastases from colorectal cancer. ISRN surgery. 2014 Feb 4;2014.

25. Renaud S, Seitlinger J, Al Lawati Y, Guerrera F, Falcoz PE, Massard G, Ferri L, Spicer J. Anatomical resections improve survival following lung metastasectomy of colorectal cancer harboring KRAS mutations. Annals of surgery. 2019 Dec 1;270(6):1170-7.

26. Renaud S, Romain B, Falcoz PE, Olland A, Santelmo N, Brigand C, Rohr S, Guenot D, Massard G. KRAS and BRAF mutations are prognostic biomarkers in patients undergoing lung metastasectomy of colorectal cancer. British journal of cancer. 2015 Feb;112(4):720.

27. Pereira AA, Rego JF, Morris V, Overman MJ, Eng C, Garrett CR, Boutin AT, Ferrarotto R, Lee M, Jiang ZQ, Hoff PM. Association between KRAS mutation and lung metastasis in advanced colorectal cancer. British journal of cancer. 2015 Feb;112(3):424-8.

28. Corsini EM, Mitchell KG, Mehran RJ, Rice DC, Sepesi B, Walsh GL, Swisher SG, Roth JA, Hofstetter WL, Vaporciyan AA, Morris VK. Colorectal cancer mutations are associated with survival and recurrence after pulmonary metastasectomy. Journal of surgical oncology. 2019 Sep 1.

29. Ghidini M, Personeni N, Bozzarelli S, Baretti M, Basso G, Bianchi P, Tronconi MC, Pressiani T, Grizzi F, Giordano L, Malesci A. KRAS mutation in lung metastases from colorectal cancer: prognostic implications. Cancer medicine. 2016 Feb;5(2):256-64.

30. Schweiger T, Hegedüs B, Nikolowsky C, Hegedüs Z, Szirtes I, Mair R, Birner P, Döme B, Lang G, Klepetko W, Ankersmit HJ. EGFR, BRAF and KRAS status in patients undergoing pulmonary metastasectomy from primary colorectal carcinoma: a prospective follow-up study. Annals of surgical oncology. 2014 Mar 1;21(3):946-54. 
31. Kim HK, Cho JH, Lee HY, Lee J, Kim J. Pulmonary metastasectomy for colorectal cancer: how many nodules, how many times?. World journal of gastroenterology: WJG. 2014 May 28;20(20):6133.

32. Liang L, Tian J, Yu Y, Wang Z, Peng K, Liu R, Wang Y, Xu X, Li H, Zhuang R, Cui Y. An Analysis of Relationship Between RAS Mutations and Prognosis of Primary Tumour Resection for Metastatic Colorectal Cancer Patients. Cellular Physiology and Biochemistry. 2018;50(2):768-82.

33. Adam R, de Haas RJ, Wicherts DA, Vibert E, Salloum C, Azoulay D, Castaing D (2011) Concomitant extrahepatic disease in patients with colorectal liver metastases: when is there a place for surgery? Ann Surg 253(2): 349-359.

34. Zabaleta J, Aguinagalde B, Fuentes MG, Bazterargui N, Izquierdo JM, Hernandez CJ, Enriquez-Navascues JM, Emparanza JI (2011) Survival after lung metastasectomy for colorectal cancer: importance of previous liver metastasis as a prognostic factor. Eur J Surg Oncol 37 (9): $786-$ 790.

35. Sclafani F, Incarbone M, Rimassa L, Personeni N, Giordano L, Alloisio M, Santoro A (2013) The role of hepatic metastases and pulmonary tumor burden in predicting survival after complete pulmonary resection for colorectal cancer. J Thorac Cardiovasc Surg 145(1): 97-103.

36. Hamaji M, Cassivi SD, Shen KR, Allen MS, Nichols FC, Deschamps C, Wigle DA (2012) Is lymph node dissection required in pulmonary metastasectomy for colorectal adenocarcinoma? Ann Thorac Surg 94(6): 1796-1800.

37. Kobayashi S, Boggon TJ, Dayaram T, Janne PA, Kocher O, Meyerson M, Johnson BE, Eck MJ, Tenen DG, Halmos B (2005) EGFR mutation and resistance of non-small-cell lung cancer to gefitinib. N Engl J Med 352(8): 786-792.

38. Peeters M, Kafatos G, Taylor A, Gastanaga VM, Oliner KS, Hechmati G, Terwey JH, van Krieken JH: Prevalence of RAS mutations and individual variation patterns among patients with metastatic colorectal cancer: A pooled analysis of randomised controlled trials. Eur J Cancer 2015;51:1704-1713.Schirripa M, Cremolini C, Loupakis F, et al. Role of NRAS mutations as prognostic and predictive markers in metastatic colorectal cancer. Int J Cancer 2015;136:8390.

39. Vincenzi B, Cremolini C, Sartore-Bianchi A, et al. Prognostic significance of K-Ras mutation rate in metastatic colorectal cancer patients. Oncotarget 2015; 6:31604-12.

40. Yaeger R, Cowell E, Chou JF, et al. RAS mutations affect pattern of metastatic spread and increase propensity for brain metastasis in colorectal cancer.Cancer 2015; 121:1195-203

41. Kim MJ, Lee HS, Kim JH, et al. Different metastatic pattern according to the KRAS mutational status and site-specific discordance of KRAS status in patients with colorectal cancer. BMC Cancer 2012; 12:347.

42. Kadowaki S, Kakuta M, Takahashi S, et al. Prognostic value of KRAS and BRAF mutations in curatively resected colorectal cancer. World J Gastroenterol $2015 ; 21: 1275-83$.

43. Deng Y, Wang L, Tan S, et al. KRAS as a predictor of poor prognosis and benefit from postoperative FOLFOX chemotherapy in patients with stage II and III colorectal cancer. Mol Oncol 2015; 9:1341-7.

44. Price TJ, Bruhn MA, Lee CK, Hardingham JE, Townsend AR, Mann KP, Simes J, Weickhardt A, Wrin JW, Wilson K, Gebski V. Correlation of extended RAS and PIK3CA gene mutation status with outcomes from the phase III AGITG MAX STUDY involving capecitabine alone or in combination with bevacizumab plus or minus mitomycin C in advanced colorectal cancer. British journal of cancer. 2015 Mar;112(6):963.

45. PIK3CA gene mutation status with outcomes from the phase III AGITG MAX STUDY involving capecitabine alone or in combination with bevacizumab plus or minus mitomycin C in advanced colorectal cancer. Br JCancer 2015; 112:963-70.

46. Tosi F, Magni E, Amatu A, Mauri G, Bencardino K, Truini M, Veronese S, De Carlis L, Ferrari G, Nichelatti M, Sartore-Bianchi A. Effect of KRAS and BRAF mutations on survival of metastatic colorectal cancer after liver resection: a systematic review and meta-analysis. Clinical colorectal cancer. 2017 Sep 1;16(3):e153-63.

47. Passiglia F, Bronte G, Bazan V, Galvano A, Vincenzi B, Russo A. Can KRAS and BRAF mutations limit the benefit of liver resection in metastatic colorectal cancer patients? A systematic review and meta-analysis. Critical reviews in oncology/hematology. 2016 Mar 1;99:150-7

48. Vauthey, J.N., et al., 2013. RAS mutation status predicts survival and patterns ofrecurrence in patients undergoing hepatectomy for colorectal liver metastases.Ann. Surg. 258, 617-626

49. Tie, J., et al., 2011. KRAS mutation is associated with lung metastasis in patientswith curatively resected colorectal cancer. Clin. Cancer Res. 17, 11221130

50. Cejas P, Lopez-Gomez M, Aguayo C, Madero R, de Castro Carpeno J, Belda-Iniesta C, Barriuso J, Moreno Garcia V, Larrauri J, Lopez R, Casado E, GonzalezBaron M, Feliu J (2009) KRAS mutations in primary colorectal cancer tumors and related metastases: a potential role in prediction of lung metastasis. PLoS One 4(12): e8199

51. Ahn, T.S., et al., 2014. The BRAF mutation is associated with the prognosis incolorectal cancer. J. Cancer Res. Clin. Oncol. 140, 1863-1871.

52. Tran, B., et al., 2011. Impact of BRAF mutation and microsatellite instability on thepattern of metastatic spread and prognosis in metastatic colorectal cancer.Cancer 117, 4623-4632

53. Sridhar, S.S., Hedley, D., Siu, L.L., 2005. Raf kinase as a target for anticancertherapeutics. Mol. Cancer Ther. 4, 677-685.

\section{Figures}




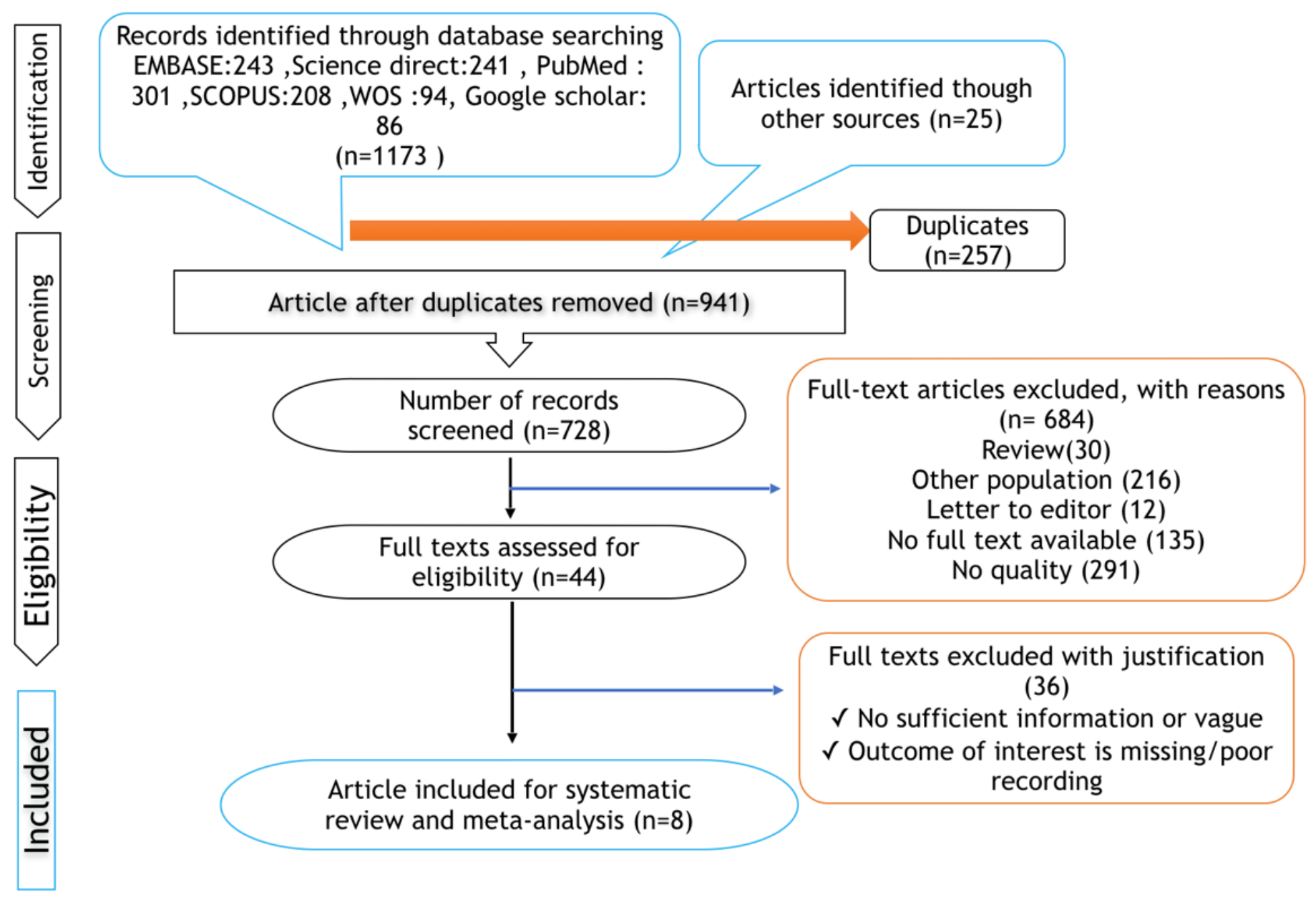

Figure 2

PRISMA flow chart describing the selection process. 


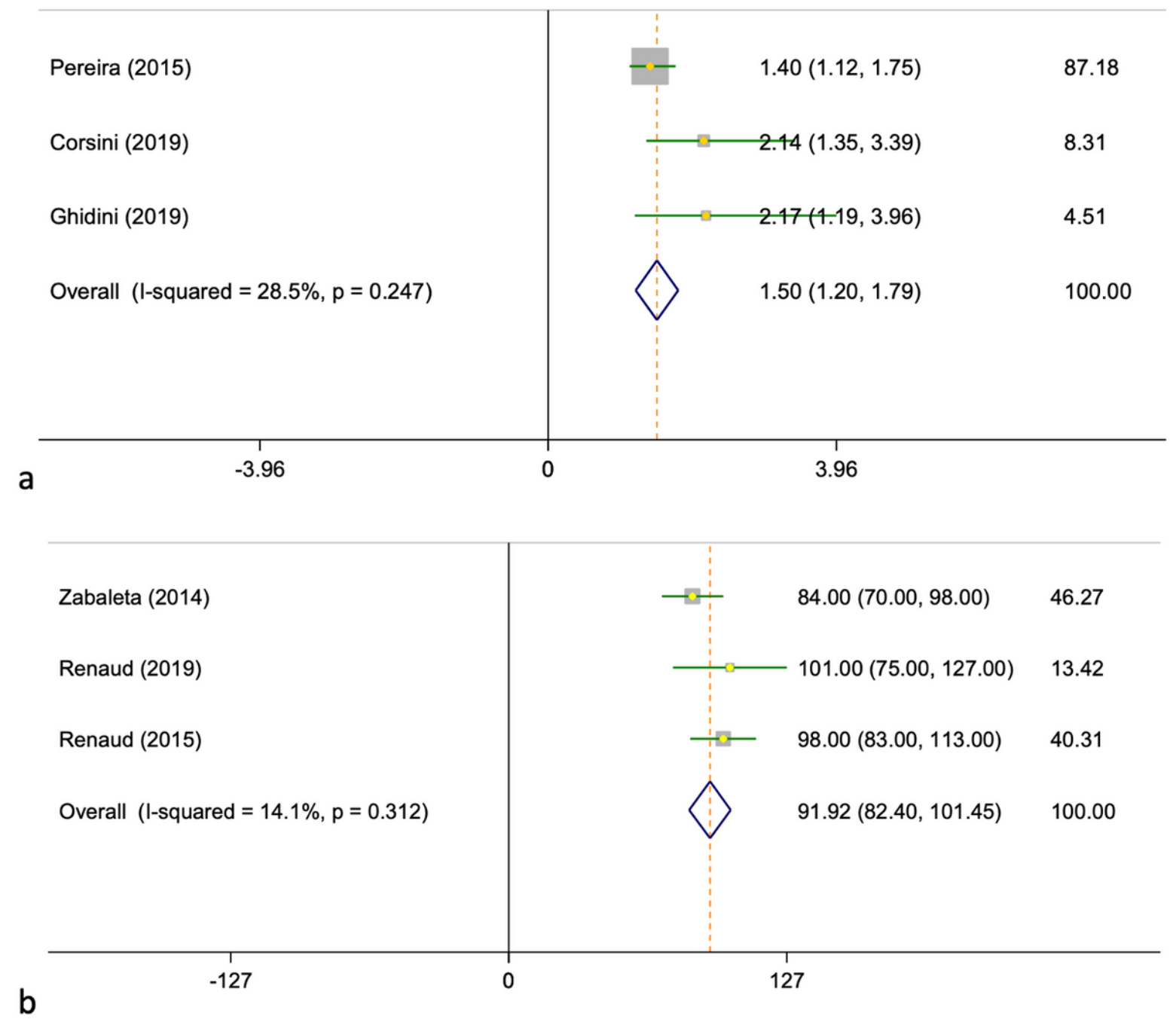

Figure 4

Forest plot of hazard ratio between KRAS mutations and OS(a) after complete resection colorectal lung metastases .Forest plot of OS (b) and its $95 \%$ interval for the studied cases based on the model of the random effects model. The midpoint of each section of the line estimates the \% value and the length of the lines showing the $95 \%$ confidence interval in each study. The oval sign shows overall mean of OS. 


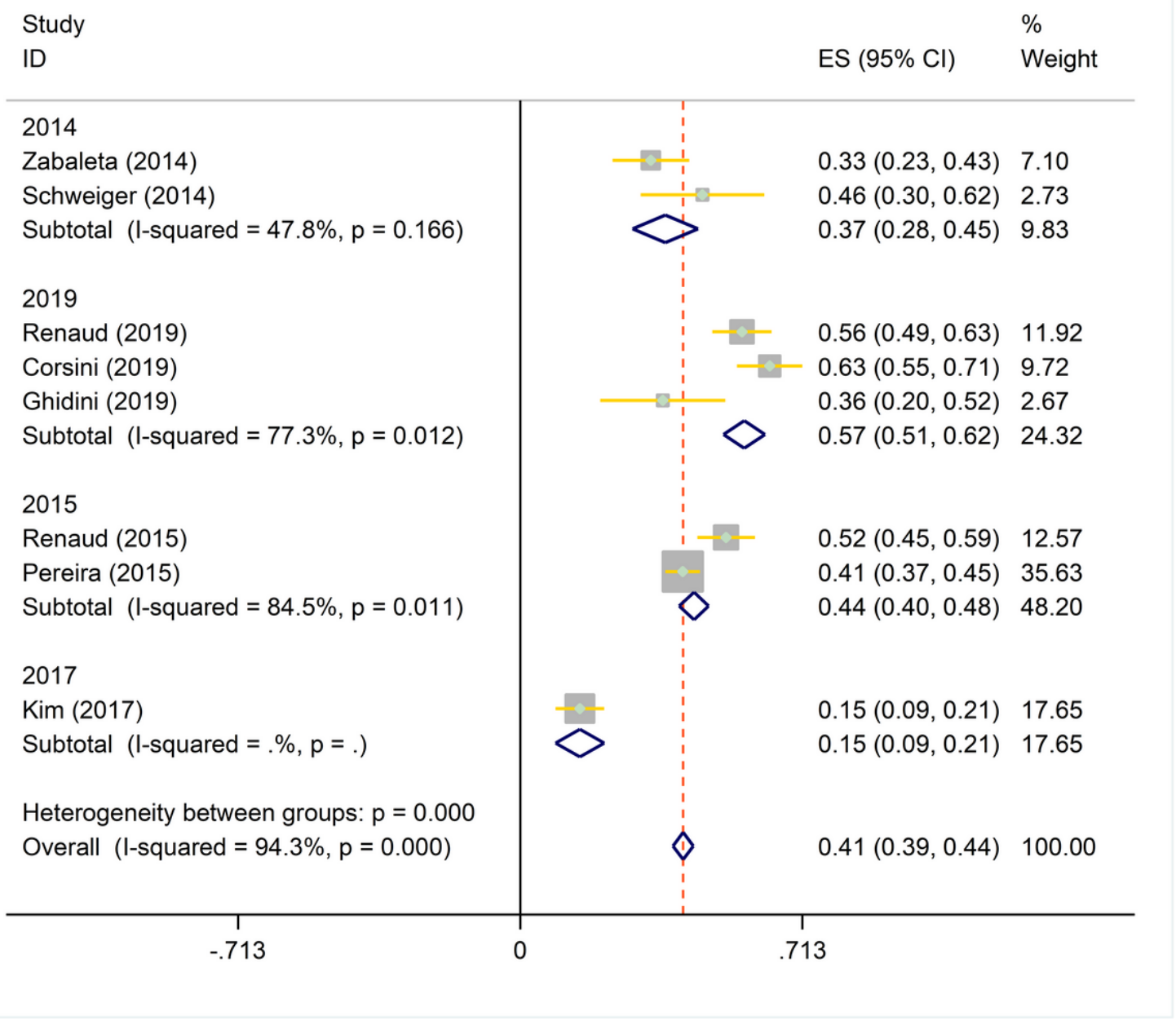

\section{Figure 6}

frequency of KRAS mutations and its $95 \%$ interval for the studied cases according to the year and the country where the study was conducted based on the model of the random effects model. The midpoint of each section of the line estimates the \% value and the length of the lines showing the $95 \%$ confidence interval in each study. The oval sign shows overall of frequency of KRAS mutations. 

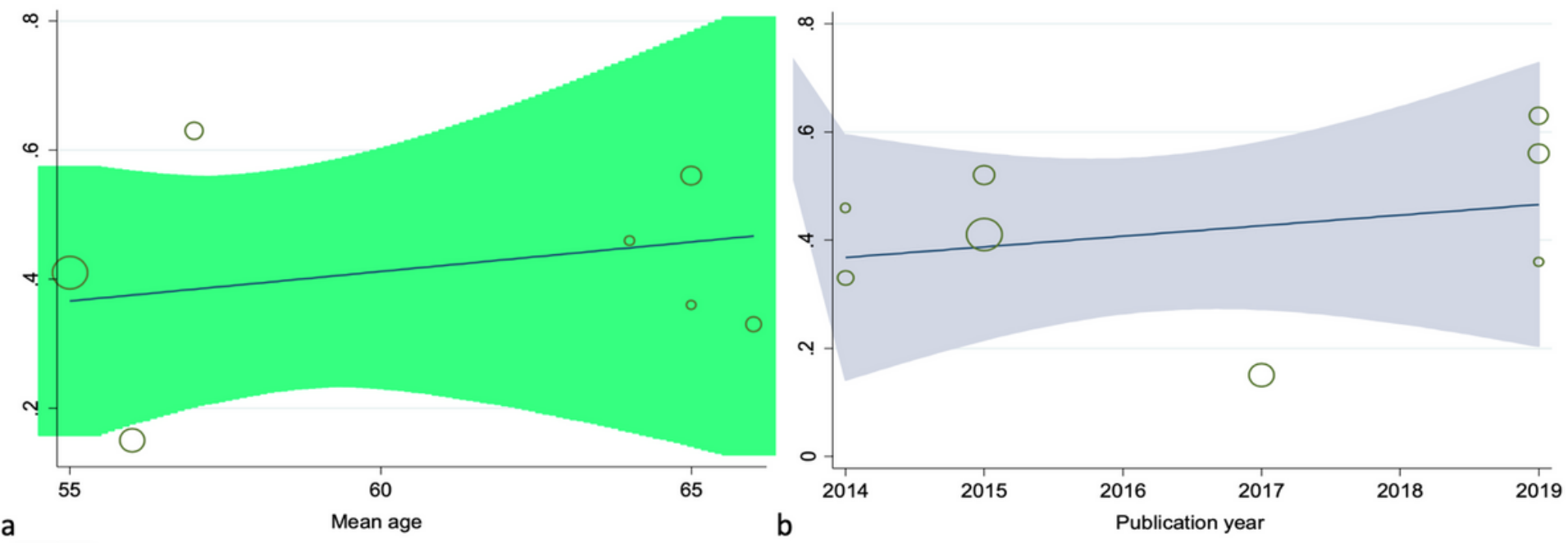

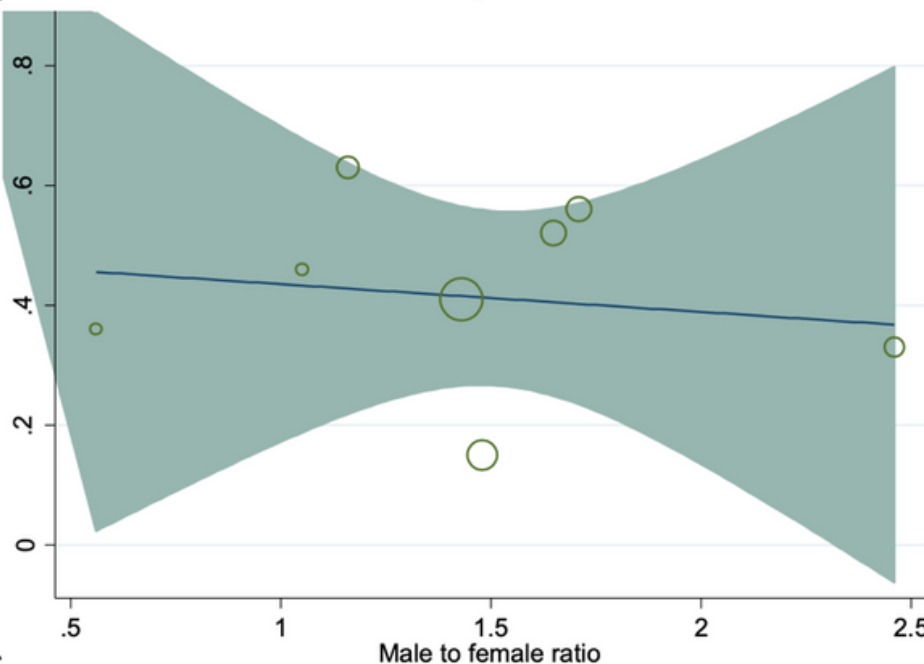

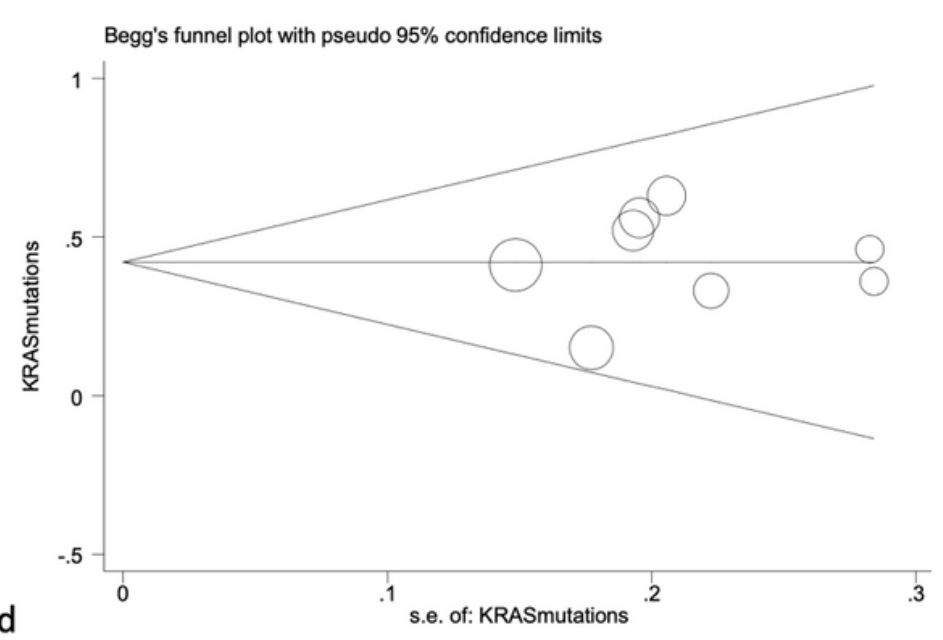

Figure 8

Meta-regression between mean age (a), publication year of study(b) , male to female ratio(c) and frequency of KRAS mutations. Funnel plot of publication bias(d) shown in symmetrically. Circles' size shows the weight of studies (bigger circles show more samples and smaller circles show fewer samples).

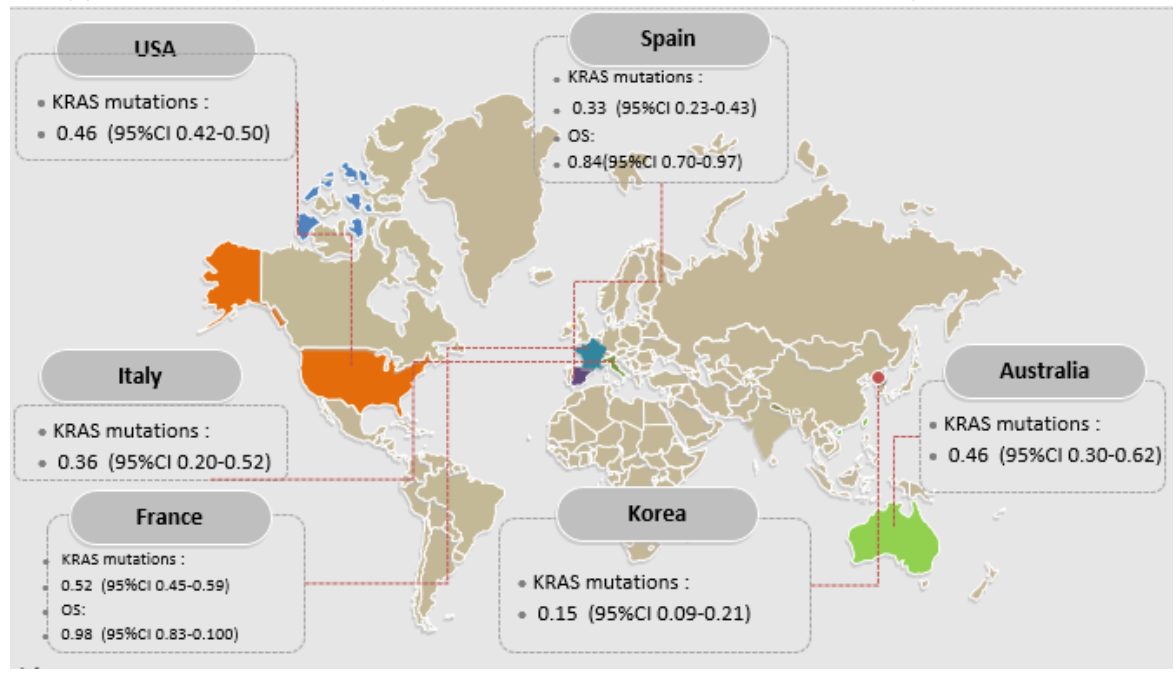

\section{Figure 10}

Frequency of KRAS mutations and OS based on the country 